\title{
CRISPR Technology for Genome Activation and Repression in Mammalian Cells
}

\author{
Dan $\mathrm{Du}^{1}$ and Lei S. $\mathrm{Qi}^{1,2,3,4}$ \\ ${ }^{1}$ Department of Bioengineering, Stanford University, Stanford, California 94305; ${ }^{2}$ Department of Chemical and \\ Systems Biology, Stanford University, Stanford, California 94305; ${ }^{3}$ ChEM-H; Stanford University, Stanford, \\ California 94305
}

Targeted modulation of transcription is necessary for understanding complex gene networks and has great potential for medical and industrial applications. CRISPR is emerging as a powerful system for targeted genome activation and repression, in addition to its use in genome editing. This protocol describes how to design, construct, and experimentally validate the function of sequence-specific single guide RNAs (sgRNAs) for sequence-specific repression (CRISPRi) or activation (CRISPRa) of transcription in mammalian cells. In this technology, the CRISPR-associated protein Cas9 is catalytically deactivated (dCas9) to provide a general platform for RNA-guided DNA targeting of any locus in the genome. Fusion of dCas9 to effector domains with distinct regulatory functions enables stable and efficient transcriptional repression or activation in mammalian cells. Delivery of multiple sgRNAs further enables activation or repression of multiple genes. By using scaffold RNAs (scRNAs), different effectors can be recruited to different genes for simultaneous activation of some and repression of others. The CRISPRi and CRISPRa methods provide powerful tools for sequence-specific control of gene expression on a genome-wide scale to aid understanding gene functions and for engineering genetic regulatory systems.

It is essential that you consult the appropriate Material Safety Data Sheets and your institution's Environmental Health and Safety Office for proper handling of equipment and hazardous materials used in this protocol.

RECIPES: Please see the end of this protocol for recipes indicated by $<R>$. Additional recipes can be found online at http://cshprotocols.cshlp.org/site/recipes.

Reagents

Chemically competent Escherichia coli cells (e.g., One Shot TOP10 Cells from Life Technologies)

dCas9 expression vector(s) appropriate for experiment

- CRISPR activation (CRISPRa) dCas9-SunTag expression vectors

Two constructs are required: a lentiviral vector containing an SV40-promoter-driven dCas 9 fusion between dCas9, $2 X$ nuclear localization signal (NLS), 10X GCN4, and a P2A-tagBFP (Addgene 60903) and a lentiviral vector containing an SV40-promoter-driven fusion protein between the single chain variable fragment (sCFV) for GCN4, a superfolder (sf) GFP, VP64, and 1X NLS (Addgene 60904).

- CRISPR interference (CRISPRi) dCas9-KRAB expression vector

This comprises a lentiviral vector containing a spleen focus-forming virus SFFV-promoter-driven dCas 9 fused to $2 X N L S$, a tagBFP and a KRAB domain (Addgene 46911).

\footnotetext{
${ }^{4}$ Correspondence: stanley.qi@stanford.edu

(C) 2016 Cold Spring Harbor Laboratory Press

Cite this protocol as Cold Spring Harb Protoc; doi:10.1101/pdb.prot090175
} 
dNTPs (10 mm)

Double-distilled water $\left(\mathrm{ddH}_{2} \mathrm{O}\right)$, sterile and nuclease-free

Dulbecco's modified Eagle's medium (DMEM), high-glucose (Life Technologies 11965-092)

Fetal bovine serum (FBS)

Gel electrophoresis reagents

Agarose gels $(1 \%, \mathrm{w} / \mathrm{v})$

DNA ladder

Ethidium bromide

Tris-acetate-EDTA (TAE) buffer $(50 \times)<\mathrm{R}>$

HEK293T cells (ATCC CRL-11268)

HEK293T cells (or other cells derived from HEK293T cells) are required for lentivirus production in Steps 26-31. In addition, they are used here as an example of target cells in Steps 32-36. Other target cells may be used as appropriate for the experiment.

In-Fusion HD Cloning Kit (Clontech 011614)

iQ SYBR Green Supermix (Bio-Rad 170-8880)

iScript cDNA Synthesis Kit (Bio-Rad 170-8890)

Lentiviral packaging plasmids pCMV-dR8.91 and pMD2.G (Addgene 12259)

At the time of this writing, $p C M V-d R 8.91$ is not avialable from Addgene. Alternatively, a lower version of the plasmid is available from Addgene (pCMV-dR8.2; Addgene 8455). Its use will not affect this protocol.

Lysogeny broth (LB) with carbenicillin (liquid medium and agar plates) $<\mathrm{R}>$

Mirus TransIT-LT1 Transfection Reagent (Mirus MIR 2300)

Opti-MEM Reduced-Serum Medium (Life Technologies 31985-062)

Penicillin-Streptomycin (100×), presterilized (Life Technologies 15070-063)

Phusion High-Fidelity Polymerase and 5× Phusion HF Buffer (New England BioLabs M0536L)

Polybrene (optional; see Step 33)

Primers

- PCR primers, one of which (sgRNA-F) contains the gene-specific sgRNA target sequence

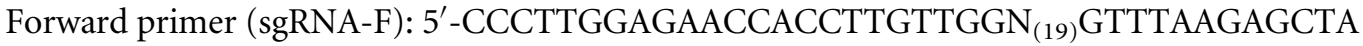
TGCTGGAAACAGCA- $3^{\prime}$

Reverse primer (sgRNA-R): 5'-GATCCTAGTACTCGAGAAAAAAAGCACCGACTCGGTG CCAC- $3^{\prime}$

For sgRNA target sequence selection, see Steps 1-3.

- Sequencing primer: 5'-GAGGCTTAATGTGCGATAAAAGA-3'

This primer binds to the mouse U6 promoter and is used to confirm the generation of sgRNA expression constructs in Step 21.

- Target gene-specific primers for qRT-PCR (see Step 40)

QIAGEN Plasmid Midi Kit (QIAGEN 12143)

It is important to use an endotoxin-free midiprep kit when purifying plasmid DNA for better transfection efficiency into mammalian cells.

QIAprep Spin Miniprep Kit (QIAGEN 27106)

QIAquick Gel Extraction Kit (QIAGEN 28706)

QIAquick PCR Purification Kit (QIAGEN 28106)

Restriction enzymes BstXI, XhoI, and DpnI

RNeasy Plus Mini Kit (QIAGEN 74134)

Single guide RNA (sgRNA) expression vector

This comprises a lentiviral vector containing the mouse U6 promoter driving SgRNA expression (Addgene 51024). It also contains an expression cassette consisting of a cytomegalovirus (CMV) promoter, a puromycinresistance gene cassette, and an mCherry gene for selection purposes.

Trypsin-EDTA (0.05\%) (e.g., Life Technologies 25300-054) 
D. Du and L.S. Qi

\section{Equipment}

Access to sequencing facility (see Step 21)

BD FACSAria II Cell Sorter (BD Biosciences) equipped with lasers and filters for detecting mCherry, EGFP, and tagBFP

CFX96 Real-Time PCR Detection System (Bio-Rad 185-5195)

$\mathrm{CO}_{2}$ incubator at $37^{\circ} \mathrm{C}$ and $5 \% \mathrm{CO}_{2}$ for mammalian cell culture

Computer with Internet-connected web browser

Conical tubes

Digital gel-imaging system

Erlenmeyer flasks $(250 \mathrm{~mL})$

Gel electrophoresis system

Glass tubes (25-mm)

Incubators at $37^{\circ} \mathrm{C}$ for growing bacteria (one standard and one capable of shaking at $200 \mathrm{rpm}$ )

Microcentrifuge

Microcentrifuge tubes

Microplate for qRT-PCR

NanoDrop 8000 UV-Vis Spectrophotometer (Thermo Scientific)

PCR tubes $(0.2-\mathrm{mL})$

Six-well tissue-culture plates

Syringe filter $(0.45-\mu \mathrm{m})$, sterile

Syringe, sterile

Thermocycler

We have implemented a computational tool, termed CRISPR-ERA ("editing, repression, and activation") for automated design of sgRNAs for given mammalian organisms, such as mouse, rat, and human (Liu et al. 2015). The CRISPR$E R A$ algorithm aligns the designed sgRNA to the whole genome and reports potential off-target sites as defined by possession of fewer than three mismatches. The tool is freely available at http://CRISPR-ERA.stanford.edu. If using CRISPR-ERA, skip Steps 1-5.

Selection of sgRNA Targets in the Genome

1. Determine the DNA sequence of the target gene using an available genome database-for example, the UCSC genome browser (Kent et al. 2002).

2. Obtain annotation information of the target gene, including the location of the transcription start site (TSS).

3. Search for patterns of $\mathrm{GN}_{(19)} \mathrm{NGG}$ around the TSS, wherein $\mathrm{GN}_{(19)}$ is the binding site of the sgRNA and NGG is the protospacer adjacent motif (PAM), which is required for efficient DNA binding of Streptococcus pyogenes Cas9.

Our sgRNA expression construct uses a mouse U6 promoter, which requires a $G$ at the very $5^{\prime}$ end for effective transcription. Therefore, we search for $G N_{(19)}$ as the binding site of the sgRNA. If another promoter is used, it is likely that the first nucleotide will be different.

The recommended window of the target DNA is -50 to +300 bp relative to the TSS for CRISPR interference (CRISPRi) for gene repression, or -400 to $-50 \mathrm{bp}$ for CRISPR activation (CRISPRa). Usually, multiple sgRNA-binding sites within the target window of the gene need to be tested to define the most efficient targeting site for repression or activation.

Many mammalian genes possess transcript isoforms with different TSSs. In this case, different sgRNAs need to be designed for each transcript. Currently, there is no direct evidence that the activities of CRISPRi and CRISPRa are sensitive to the DNA strand or GC content (Gilbert et al. 2014). 


\section{Design of sgRNA Sequences}

4. Ensure that the base-pairing sequence on the sgRNA is the reverse complement of the $\mathrm{GN}_{(19)}$ sequence identified in Step 3.

5. Analyze the specificity of the target sequence in the genome use the basic local alignment search tool (BLAST; http://blast.ncbi.nlm.nih.gov) (Bhagwat et al. 2012).

The BLAST algorithm enables the specificity of sgRNA targeting in the genome to be analyzed when not using the CRISPR-ERA tool.

6. Generate the full-length sgRNA by appending $\mathrm{GN}_{(19)} 3^{\prime}$ to the rest of the optimized sgRNA sequence $\left(5^{\prime}-\mathrm{GN}_{(19)}\right.$ GUUUAAGAGCUAUGCUGGAAACAGCATAGCAAGUUUAAAUAAGG CUAGUCCGUUAUCAACUUGAAAAAGUGGCACCGAGUCGGUGCUUUUUUU-3') (Chen et al. 2013).

7. Confirm that the $\mathrm{GN}_{(19)}$ target sequence does not contain any transcription termination sequence for the U6 promoter (Paul et al. 2002).

\section{Preparation of sgRNA Expression Constructs}

8. Generate the sgRNA backbone by digesting the empty sgRNA expression vector with restriction enzymes BstXI and XhoI for $4-16 \mathrm{~h}$ at $37^{\circ} \mathrm{C}$ according to the manufacturer's instructions.

9. Separate the digested sgRNA backbone products by electrophoresis through a $1 \%(w / v)$ agarose gel in $1 \times$ TAE buffer. Stain the gel with ethidium bromide, and visualize the bands using a digital gel imaging system. Compare the bands to those of a proper DNA ladder, and confirm that the band representing the sgRNA backbone DNA is $\sim 8 \mathrm{~kb}$.

10. Gel-purify the sgRNA backbone DNA using a QIAquick Gel Extraction Kit according to the manufacturer's instructions. Store the DNA at $-20^{\circ} \mathrm{C}$ until use in Step 15.

11. Perform PCR as follows, using primers that contain the 20-nt target sequences identified in Steps 1-3.

i. Assemble the following reaction (volumes shown are for one reaction) in a $0.2-\mathrm{mL}$ PCR tube on ice.

$\begin{array}{ll}0.5 \mu \mathrm{L} & \text { Empty sgRNA expression vector (undigested) as template }(100 \mathrm{ng} / \mu \mathrm{L}) \\ 2.5 \mu \mathrm{L} & \text { Forward primer (sgRNA-F) }(10 \mu \mathrm{M}) \\ 2.5 \mu \mathrm{L} & \text { Reverse primer }(\text { sgRNA-R) }(10 \mu \mathrm{M}) \\ 2 \mu \mathrm{L} & \text { dNTPs }(10 \mathrm{~mm}) \\ 0.5 \mu \mathrm{L} & \text { Phusion High-Fidelity Polymerase }(2 \mathrm{U} / \mu \mathrm{L}) \\ 10 \mu \mathrm{L} & \text { Phusion HF Buffer }(5 \times) \\ 32 \mu \mathrm{L} & \text { Nuclease-free water } \\ 50 \mu \mathrm{L} & \text { Total volume }\end{array}$

ii. Perform PCR with the following cycling conditions:

$\begin{array}{lll}1 \text { cycle } & 98^{\circ} \mathrm{C} & 30 \mathrm{sec} \\ 25 \text { cycles } & 98^{\circ} \mathrm{C} & 10 \mathrm{sec} \\ & 62^{\circ} \mathrm{C} & 30 \mathrm{sec} \\ & 72^{\circ} \mathrm{C} & 10 \mathrm{sec} \\ 1 \text { cycle } & 72^{\circ} \mathrm{C} & 5 \mathrm{~min} \\ 1 \text { cycle } & 4^{\circ} \mathrm{C} & \text { Forever }\end{array}$

12. Confirm that the PCRs successfully amplified a $\sim 150$-bp DNA product by separating $5 \mu \mathrm{L}$ of the PCR products on a $1 \%$ agarose gel as in Step 9. 
D. Du and L.S. Qi

13. Add $1 \mu \mathrm{L}$ of DpnI $(20 \mathrm{U} / \mu \mathrm{L})$ into each PCR and then incubate for $1 \mathrm{~h}$ at $37^{\circ} \mathrm{C}$. Treatment of Dpnl will digest the PCR templates.

14. Purify the PCRs using a QIAquick PCR Purification Kit by following the manufacturer's instructions. Store the DNA at $-20^{\circ} \mathrm{C}$ until use in Step 15 .

15. Measure the concentrations of the purified sgRNA backbone DNA (from Step 10) and PCR fragments (from Step 14) using a NanoDrop UV-Vis 8000 Spectrophotometer.

16. Ligate the PCR fragments to the sgRNA backbone DNA using an In-Fusion HD Cloning Kit.

i. Assemble the cloning reaction.

$\begin{array}{ll}1 \mu \mathrm{L} & \text { In-Fusion HD Enzyme Premix (5X) } \\ 50 \mathrm{ng} & \text { Linearized sgRNA backbone DNA (from Step 10) } \\ 25 \mathrm{ng} & \text { Purified PCR fragments (from Step 14) } \\ x \mu \mathrm{L} & \mathrm{ddH}_{2} \mathrm{O} \\ 5 \mu \mathrm{L} & \text { Total volume }\end{array}$

ii. Incubate the reaction for $15 \mathrm{~min}$ at $50^{\circ} \mathrm{C}$ using a thermocycler.

iii. Place on ice for $5 \mathrm{~min}$. Store at $-20^{\circ} \mathrm{C}$ until use in Step 17.

17. Transform chemically competent $E$. coli cells with the products of the ligation reactions. Follow the manufacturer's instructions for the E. coli cells. Spread transformed E. coli cells onto LB agar plates supplemented with $100 \mu \mathrm{g} / \mathrm{mL}$ carbenicillin. Incubate the plates overnight in a $37^{\circ} \mathrm{C}$ incubator.

18. Transfer single colonies into $25-\mathrm{mm}$ glass tubes containing $5 \mathrm{~mL}$ of $\mathrm{LB}$ medium supplemented with $100 \mu \mathrm{g} / \mathrm{mL}$ carbenicillin. For each colony, use a sterile pipette tip to touch the colony, and then swirl the tip in the LB medium to dissolve the colony. Incubate overnight in a $37^{\circ} \mathrm{C}$ shaking incubator, swirling at $200 \mathrm{rpm}$.

19. Transfer $0.5 \mathrm{~mL}$ of bacterial culture into a $250-\mathrm{mL}$ Erlenmeyer flask containing $50 \mathrm{~mL}$ of LB medium with $100 \mu \mathrm{g} / \mathrm{mL}$ carbenicillin. Incubate overnight in a $37^{\circ} \mathrm{C}$ shaking incubator, swirling at $200 \mathrm{rpm}$.

20. Extract the plasmid DNA from the remaining $4.5 \mathrm{~mL}$ of bacterial culture using a QIAprep Spin Miniprep Kit according to the manufacturer's instructions.

21. Send the extracted plasmid DNA for sequencing with the sequencing primer.

22. After the plasmid is verified by sequencing, extract DNA from the 50-mL bacterial culture using a QIAGEN Plasmid Midi Kit according to the manufacturer's instructions. Store the DNA at $-20^{\circ} \mathrm{C}$ until use in Step 27.

\section{Preparation of dCas9 Expression Vectors}

23. Transform chemically competent E. coli cells with the dCas9 expression vectors appropriate for the experiment (CRISPRi or CRISPRa). Spread transformed E. coli cells onto LB agar plates supplemented with $100 \mu \mathrm{g} / \mathrm{mL}$ carbenicillin. Incubate the plates overnight in a $37^{\circ} \mathrm{C}$ incubator.

24. Transfer a single colony into $50 \mathrm{~mL}$ of LB medium supplemented with $100 \mu \mathrm{g} / \mathrm{mL}$ carbenicillin. Incubate overnight in a $37^{\circ} \mathrm{C}$ shaking incubator, swirling at $200 \mathrm{rpm}$.

25. Extract DNA using a QIAGEN Plasmid Midi Kit according to the manufacturer's instructions. Store the DNA at $-20^{\circ} \mathrm{C}$ until use in Step 27.

Packaging of dCas9 and sgRNA Expression Constructs into Lentiviral Particles

If more lentiviruses are required, scale up the cell numbers, DNA amounts, and transfection reagent volumes used here. 
26. On the day before transfection, seed a six-well tissue-culture plate with $2-3 \times 10^{5}$ HEK293T cells in $2 \mathrm{~mL}$ of high-glucose DMEM containing $10 \%(\mathrm{v} / \mathrm{v}) \mathrm{FBS}$ per well. Incubate overnight at $37^{\circ} \mathrm{C}$ and $5 \% \mathrm{CO}_{2}$.

HEK293T cells can be maintained in regular high-glucose DMEM medium supplemented with $10 \%(\mathrm{v} / \mathrm{v})$ FBS, $100 \mathrm{U} / \mathrm{mL}$ streptomycin, and $100 \mu \mathrm{g} / \mathrm{mL}$ penicillin and regularly passaged using $0.05 \%(\mathrm{w} / \mathrm{v})$ trypsinEDTA. However, antibiotic-free DMEM is required during transfection and virus collection to achieve better efficiency.

27. Twenty-four hours after plating the cells, prepare the transfection complexes as follows.

i. Combine the following DNA samples.

$1.32 \mu \mathrm{g} \quad$ pCMV-dR8.91 (lentiviral packaging plasmid)

$165 \mathrm{ng} \quad$ pMD2.G (lentiviral packaging plasmid)

$1.51 \mu \mathrm{g} \quad \mathrm{dCas} 9$ or sgRNA expression construct

Nontargeting sgRNA vector or $d$ Cas 9 without fusion vector can be used in parallel as a negative control.

ii. Add this 3- $\mu$ g DNA mixture into $250 \mu \mathrm{L}$ of Opti-MEM Reduced-Serum Medium in a microcentrifuge tube. Mix well by pipetting up and down.

iii. Add 7.5 $\mu \mathrm{L}$ of Mirus TransIT-LT1 Transfection Reagent into the same tube. Mix well by pipetting up and down.

iv. Allow transfection complexes to form for $30 \mathrm{~min}$ at room temperature.

28. Remove $250 \mu \mathrm{L}$ of medium from each well in the six-well plate.

29. Add the $\sim 250-\mu \mathrm{L}$ mixture from Step 27 .iv into one well in the six-well plate. Mix well by rocking the plate gently back and forth. Incubate for $24 \mathrm{~h}$ at $37^{\circ} \mathrm{C}$ and $5 \% \mathrm{CO}_{2}$.

Cells will begin producing viruses $24 \mathrm{~h}$ after transfection.

30. After the 24-h incubation, replace the transfection medium with $2.5 \mathrm{~mL}$ of fresh DMEM with $10 \%$ FBS.

If the target cells to be infected have any additional medium requirements, replace the transfection medium with $2.5 \mathrm{~mL}$ of special growth medium for the target cells.

31. Use a sterile syringe to harvest the viral supernatant $24-48 \mathrm{~h}$ after medium replacement. Filter the medium through a $0.45-\mu \mathrm{m}$ syringe filter into a conical tube to avoid transferring HEK293T cells.

The total volume will be $\sim 2 \mathrm{~mL}$ after filtering. Lentiviral particles can be stored for up to $1 \mathrm{wk}$ at $4^{\circ} \mathrm{C}$, or snapfrozen in liquid nitrogen and stored for several months at $-80^{\circ} \mathrm{C}$. However, we recommend using the lentiviruses immediately after collection.

Transduction of Target Cells with dCas9 and sgRNA Lentiviral Particles

In the following, the use of HEK293T cells is given as an example. For other types of cells, modify the procedure (e.g., cell number and growth medium) as appropriate.

32. Sixteen hours before transduction, seed a six-well tissue-culture plate with $1.5-2 \times 10^{5}$ HEK293T cells in $2 \mathrm{~mL}$ of high-glucose DMEM supplemented with $10 \%$ FBS per well. Incubate at $37^{\circ} \mathrm{C}$ and $5 \% \mathrm{CO}_{2}$.

33. Replace the medium with $1 \mathrm{~mL}$ of DMEM containing $10 \%$ FBS and $1 \mathrm{~mL}$ of filtered viral supernatant. Incubate overnight at $37^{\circ} \mathrm{C}$ and $5 \% \mathrm{CO}_{2}$.

Depending on the virus titration, the viral supernatant can be diluted with growth medium for the target cells. Polybrene can be used to promote the infection efficiency with proper concentration; however, it is toxic for some types of cells, including HEK293T cells.

34. Replace the viral supernatant with $2 \mathrm{~mL}$ of fresh DMEM with $10 \%$ FBS, and incubate for $48 \mathrm{~h}$ at $37^{\circ} \mathrm{C}$ and $5 \% \mathrm{CO}_{2}$. 
D. Du and L.S. Qi

Cells usually will express $d$ Cas9 protein $48 \mathrm{~h}$ after addition of lentiviruses. However, for repression experiments, we suggest collecting cells at least $72 \mathrm{~h}$ after infection to minimize the interference by preexisting target gene mRNA. If necessary, split the cells when they reach $80 \%-90 \%$ confluence before sorting.

35. Use a BD FACSAria II Cell Sorter to collect the cells.

- For the CRISPRi system, collect cells positive for both blue fluorescent protein (BFP) and mCherry.

The BFP-positive cells should express dCas9 protein, and mCherry-positive cells should express sgRNA.

- For the CRISPRa (dCas9-Suntag) system, collect cells that are positive for BFP, mCherry, and GFP.

The GFP-positive cells should express scFv-sfGFP-VP64 fusion protein.

36. Incubate the collected cells at $37^{\circ} \mathrm{C}$ and $5 \% \mathrm{CO}_{2}$.

After the cells are grown up, analyze the expression levels of target genes by qRT-PCR as described in Steps 37-40.

Quantification of the Effects of CRISPRi or CRISPRa on Gene Expression in Target Cells

37. Extract total RNA from the cells infected using an RNeasy Plus Mini Kit according to the manufacturer's instructions.

Typically, $0.5-1 \times 10^{6}$ cells $(50 \%-80 \%$ confluence of cells in one well in a six-well plate) are sufficient for total RNA extraction.

38. Measure the concentrations of the total RNA samples using a NanoDrop spectrophotometer.

39. Synthesize cDNA using an iScript cDNA Synthesis Kit.

i. Set up the cDNA synthesis reaction.

$4 \mu \mathrm{L} \quad$ iScript reaction mix $(5 \times)$

$1 \mu \mathrm{L} \quad$ iScript reverse transcriptase

$1 \mu \mathrm{g} \quad$ Total RNA template

$x \mu \mathrm{L} \quad$ Nuclease-free water

$20 \mu \mathrm{L} \quad$ Total volume

ii. Incubate the reaction as follows (e.g., using a thermocycler):

$\begin{array}{lll}1 \text { cycle } & 25^{\circ} \mathrm{C} & 5 \mathrm{~min} \\ 1 \text { cycle } & 42^{\circ} \mathrm{C} & 30 \mathrm{~min} \\ 1 \text { cycle } & 85^{\circ} \mathrm{C} & 5 \mathrm{~min} \\ 1 \text { cycle } & 4{ }^{\circ} \mathrm{C} & \text { Forever }\end{array}$

iii. Store the DNA at $-20^{\circ} \mathrm{C}$ until use in Step 40.i.

40. Analyze the cDNA levels of target genes using a standard qRT-PCR protocol.

i. Set up the PCR in a microplate using the iQ SYBR Green Supermix according to the manufacturer's instructions.

$10 \mu \mathrm{L} \quad$ iQ SYBR Green Supermix (2x)

$1.2 \mu \mathrm{L} \quad$ Forward primer (target gene-specific; $5 \mu \mathrm{M}$ )

$1.2 \mu \mathrm{L} \quad$ Reverse primer (target gene-specific; $5 \mu \mathrm{M}$ )

$0.25 \mu \mathrm{L} \quad$ Template (cDNA from Step 39)

$7.35 \mu \mathrm{L} \quad$ Nuclease-free water

$20 \mu \mathrm{L} \quad$ Total volume

The amount of template cDNA can be scaled up or down according to the expression levels of the target genes in the cells. Housekeeping genes-for example, GAPDH, encoding glyceraldehyde-3-phosphate dehydrogenase-should be used as references. 
ii. Run the following real-time PCR profile in a CFX96 Real-Time PCR Detection System.

$\begin{array}{lll}1 \text { cycle } & 95^{\circ} \mathrm{C} & 2-3 \mathrm{~min} \\ 39 \text { cycles } & 95^{\circ} \mathrm{C} & 10-15 \mathrm{sec} \\ & 55^{\circ} \mathrm{C}-60^{\circ} \mathrm{C} & 15-30 \mathrm{sec} \\ & 72^{\circ} \mathrm{C} & 30 \mathrm{sec} \\ \text { Melt curve (optional) } & 55^{\circ} \mathrm{C}-95^{\circ} \mathrm{C} \text { (in } 0.5^{\circ} \mathrm{C} \text { increments) } & 10-30 \mathrm{sec}\end{array}$

iii. Analyze the qRT-PCR data by standard methods to obtain the relative transcriptional expression levels of the target genes regulated by CRISPRi/a.

We use the $2^{-\Delta \Delta C t}$ method to obtain the relative mRNA expression level of the CRISPRi or CRISPRa sample vs. a control sample, where $\Delta \Delta C t=\Delta C t$ (CRISPRi/a sample)- $\Delta C t$ (control sample, e.g., nontargeting sgRNA sample), and where $\Delta C t$ (sample) $=C t$ (any sample)-Ct(endogenous housekeeping gene).

To date, several tools have been developed to functionally interrogate gene expression. RNAi has been shown to disrupt gene expression by triggering the degradation of target mRNAs (Chang et al. 2006). However, the technique is somewhat limited in its application owing to off-target effects and through being restricted to cytosolic target mRNAs (Jackson et al. 2003; Adamson et al. 2012; Sigoillot et al. 2012). Protein-based tools are difficult to be designed, cloned, and delivered into target cells. The complex programming and limited targeting sites also restrict the application of zinc fingers and tools based on transcription-activator-like effectors (TALEs) for perturbing the expression of multiple genes. Loss-of-function approaches based on genome editing, such as CRISPR-Cas9, cause irreversible frameshift disruptions, cytotoxic double-stranded DNA breaks, and in-frame insertion-deletions (indels) arising from error-prone DNA repair. These could limit the ability of the CRISPR technique to completely abolish the function of genes and noncoding RNAs (Huang et al. 1996; Jackson 2002; Koike-Yusa et al. 2014; Shalem et al. 2014; Wang et al. 2014).

In contrast, RNA-guided DNA targeting of the dCas9 protein to a specific locus provides a programmable platform to modulate genome status while generating minimal off-target effects. Fusion of different effector domains to dCas9 enables transcriptional repression (CRISPRi) or activation (CRISPRa) of specific target genes. CRISPRi and CRISPRa enable inducible and reversible modulation of specific endogenous gene expression within an intact biological system. The modulation of the transcription of single or multiple genes can be specifically achieved by delivery of multiple sgRNAs (Gilbert et al. 2013, 2014; Qi et al. 2013; Tanenbaum et al. 2014; Zalatan et al. 2015). By using scRNA, transcriptional activation or repression of different target genes can be achieved simultaneously in the same cell (Zalatan et al. 2015). Recently, CRISPRa has been used to effectively activate expression of target genes in plants and flies (Lin et al. 2015; Lowder et al. 2015). Furthermore, Kleinstiver and colleagues have modified S. pyogenes Cas9 (spCas9) to recognize alternative PAM sequences (other than NGG) by using a selection-based approach in bacterial cells (Kleinstiver et al. 2015). This provides researchers an expanded targetable sequence space in the genome for using CRISPR-dCas9. Thus, owing to its simplicity and flexibility, CRISPRi or CRISPRa can facilitate genome-scale perturbation of gene expression (Gilbert et al. 2014; Konermann et al. 2015).

However, the detailed mechanism underlying how CRISPRi and CRISPRa components interact with local transcriptional machinery and epigenetic factors is not well established. We usually design three to five sgRNAs for each target transcript and choose the best one for functional analysis. The reason why some of the designed sgRNAs have no function and why the efficiency of different designed sgRNAs varies is not clear. Knowledge of the mechanism would assist the efficiency of designing functional sgRNAs. Moreover, the spCas9 protein, which is widely used for transcriptional modulation, is a large molecule that is difficult to clone and package with the necessary regulatory elements into a size-restricted virus, such as the adeno-associated virus (AAV) that has been generally 
D. Du and L.S. Qi

used for gene therapy. In contrast, the smaller ortholog Staphylococcus aureus Cas9 (saCas9) has been shown to edit the targets efficiently and to be compatible with the AAV system, which has also been engineered as a transcriptional activating system (SAM) (Nishimasu et al. 2015; Ran et al. 2015). Currently, the gene-regulatory tools based on the S. aureus dCas9 are being developed for moreefficient transcriptional repression and activation. Thus, in summary, CRISPRi and CRISPRa based on different species of Cas 9 or its homologs provide a versatile platform to manipulate and interrogate gene expression systematically.

\section{RECIPES}

Lysogeny Broth (LB) with Carbenicillin

Reagent Quantity

$\begin{array}{ll}\text { Agar (for plates only) } & 20 \mathrm{~g}\end{array}$

$\mathrm{NaCl} \quad 10 \mathrm{~g}$

Tryptone $10 \mathrm{~g}$

Yeast extract $\quad 5 \mathrm{~g}$

Prepare the above-listed ingredients in $1 \mathrm{~L}$ of deionized water. Adjust the $\mathrm{pH}$ to 7.0 with $5 \mathrm{~N} \mathrm{NaOH}$. Autoclave for $20 \mathrm{~min}$ at $15 \mathrm{psi}\left(1.05 \mathrm{~kg} / \mathrm{cm}^{2}\right)$. Cool to $\sim 60^{\circ} \mathrm{C}$ and add carbenicillin (final concentration $100 \mu \mathrm{g} / \mathrm{mL}$ ). Pour the medium into Petri dishes ( $\sim 25 \mathrm{~mL}$ per 100 -mm plate). Store the LB plates at $4^{\circ} \mathrm{C}$; they will keep for at least 4 mo.

Tris-Acetate-EDTA (TAE) Buffer (50×)

Reagent

Final concentration $(1 \times)$

$\begin{array}{lr}\text { Tris base } & 40 \mathrm{~mm} \\ \text { EDTA } & 2 \mathrm{~mm} \\ \text { Acetic acid } & 20 \mathrm{~mm}\end{array}$

Adjust to $\mathrm{pH} 8.5$ and dilute to $1 \times$ with Milli-Q $\mathrm{H}_{2} \mathrm{O}$ before use.

\section{REFERENCES}

Adamson B, Smogorzewska A, Sigoillot FD, King RW, Elledge SJ. 2012. A genome-wide homologous recombination screen identifies the RNAbinding protein RBMX as a component of the DNA-damage response. Nat Cell Biol 14: 318-328.

Bhagwat M, Young L, Robison R.R. 2012. Using BLAT to find sequence similarity in closely related genomes. Curr Protoc Bioinformatics Chapter 10: Unit 10.18.

Chang K, Elledge SJ, Hannon GJ. 2006. Lessons from Nature: MicroRNAbased shRNA libraries. Nat Methods 3: 707-714.

Chen B, Gilbert LA, Cimini BA, Schnitzbauer J, Zhang W, Li GW, Park J, Blackburn EH, Weissman JS, Qi LS, et al. 2013. Dynamic imaging of genomic loci in living human cells by an optimized CRISPR/Cas system. Cell 155: 1479-1491.

Gilbert LA, Larson MH, Morsut L, Liu Z, Brar GA, Torres SE, Stern-Ginossar N, Brandman O, Whitehead EH, Doudna JA, et al. 2013. CRISPRmediated modular RNA-guided regulation of transcription in eukaryotes. Cell 154: 442-451.

Gilbert LA, Horlbeck MA, Adamson B, Villalta JE, Chen Y, Whitehead EH, Guimaraes C, Panning B, Ploegh HL, Bassik MC, et al. 2014. Genomescale CRISPR-mediated control of gene repression and activation. Cell 159: $647-661$.

Huang LC, Clarkin KC, Wahl GM. 1996. Sensitivity and selectivity of the DNA damage sensor responsible for activating p53-dependent G1 arrest. Proc Natl Acad Sci 93: 4827-4832.

Jackson SP. 2002. Sensing and repairing DNA double-strand breaks. Carcinogenesis 23: 687-696.
Jackson AL, Bartz SR, Schelter J, Kobayashi SV, Burchard J, Mao M, Li B, Cavet G, Linsley PS. 2003. Expression profiling reveals off-target gene regulation by RNAi. Nat Biotechnol 21: 635-637.

Kent WJ, Sugnet CW, Furey TS, Roskin KM, Pringle TH, Zahler AM, Haussler D. 2002. The human genome browser at UCSC. Genome Res 12: 996-1006.

Kleinstiver BP, Prew MS, Tsai SQ, Topkar VV, Nguyen NT, Zheng Z, Gonzales AP, Li Z, Peterson RT, Yeh JR, et al. 2015. Engineered CRISPRCas9 nucleases with altered PAM specificities. Nature 523: 481-485.

Koike-Yusa H, Li Y, Tan EP, Velasco-Herrera Mdel C, Yusa K. 2014. Genome-wide recessive genetic screening in mammalian cells with a lentiviral CRISPR-guide RNA library. Nat Biotechnol 32: 267-273.

Konermann S, Brigham MD, Trevino AE, Joung J, Abudayyeh OO, Barcena C, Hsu PD, Habib N, Gootenberg JS, Nishimasu H, et al. 2015. Genome-scale transcriptional activation by an engineered CRISPRCas9 complex. Nature 517: 583-588.

Lin S, Ewen-Campen B, Ni X, Housden BE, Perrimon N. 2015. In vivo transcriptional activation using CRISPR-Cas9 in Drosophila. Genetics 201: 433-442.

Liu H, Wei Z, Dominguez A, Li Y, Wang X, Qi LS. 2015. CRISPR-ERA: A comprehensive disign tool for CRISPR-mediated gene editing, repression, and activation. Bioinformatics 31: 3676-3678.

Lowder LG, Zhang D, Baltes NJ, Paul JW III, Tang X, Zheng X, Voytas DF, Hsieh TF, Zhang Y, Qi Y. 2015. A CRISPR/Cas9 toolbox for multiplexed plant genome editing and transcriptional regulation. Plant Physiol 169: 971-985. 
Nishimasu H, Cong L, Yan WX, Ran FA, Zetsche B, Li Y, Kurabayashi A Ishitani R, Zhang F, Nureki O. 2015. Crystal structure of Staphylococcus aureus Cas9. Cell 162: 1113-1126.

Paul CP, Good PD, Winer I, Engelke DR. 2002. Effective expression of small interfering RNA in human cells. Nat Biotechnol 20: 505-508.

Qi LS, Larson MH, Gilbert LA, Doudna JA, Weissman JS, Arkin AP, Lim WA. 2013. Repurposing CRISPR as an RNA-guided platform for sequence-specific control of gene expression. Cell 152: 11731183.

Ran FA, Cong L, Yan WX, Scott DA, Gootenberg JS, Kriz AJ, Zetsche B, Shalem O, Wu X, Makarova KS, et al. 2015. In vivo genome editing using Staphylococcus aureus Cas9. Nature 520: 186-191.

Shalem O, Sanjana NE, Hartenian E, Shi X, Scott DA, Mikkelsen TS, Heckl D, Ebert BL, Root DE, Doench JG, et al. 2014. Genome-scale
CRISPR-Cas9 knockout screening in human cells. Science 343: 8487.

Sigoillot FD, Lyman S, Huckins JF, Adamson B, Chung E, Quattrochi B, King RW. 2012. A bioinformatics method identifies prominent offtargeted transcripts in RNAi screens. Nat Methods 9: 363-366.

Tanenbaum ME, Gilbert LA, Qi LS, Weissman JS, Vale RD. 2014. A proteintagging system for signal amplification in gene expression and fluorescence imaging. Cell 159: 635-646.

Wang T, Wei JJ, Sabatini DM, Lander ES. 2014. Genetic screens in human cells using the CRISPR-Cas9 system. Science 343: 80-84.

Zalatan JG, Lee ME, Almeida R, Gilbert LA, Whitehead EH, La Russa M, Tsai JC, Weissman JS, Dueber JE, Qi LS, et al. 2015. Engineering complex synthetic transcriptional programs with CRISPR RNA scaffolds. Cell 160: 339-350. 


\section{CRISPR Technology for Genome Activation and Repression in Mammalian Cells}

Dan Du and Lei S. Qi

Cold Spring Harb Protoc; doi: 10.1101/pdb.prot090175

\begin{tabular}{|c|c|}
\hline $\begin{array}{r}\text { Email Alerting } \\
\text { Service }\end{array}$ & Receive free email alerts when new articles cite this article - click here. \\
\hline $\begin{array}{l}\text { Subject } \\
\text { Categories }\end{array}$ & $\begin{array}{l}\text { Browse articles on similar topics from Cold Spring Harbor Protocols. } \\
\text { Analysis of Gene Expression (197 articles) } \\
\text { Analysis of Gene Expression in Cultured Cells (66 articles) } \\
\text { Analysis of Gene Expression, general (129 articles) } \\
\text { Expression of Cloned Genes (80 articles) } \\
\text { Molecular Biology, general (1293 articles) }\end{array}$ \\
\hline
\end{tabular}

